\title{
Charge transfer in trans-combretastatins
}

\author{
Nicole Holzmann, Leonardo Bernasconi, Kathrin M. Callaghan, \\ Roger H. Bisby and Anthony W. Parker
}

\section{Published version information}

Citation: N Holzmann et al. "Charge transfer in trans-combretastatins." Chemical Physics Letters vol. 692 (2018): 146-151.

DOI: $\underline{10.1016 / \text { i.cplett.2017.12.028 }}$

C2017. This manuscript version is made available under the CC-BY-NC-ND 4.0 Licence.

This version is made available in accordance with publisher policies. Please cite only the published version using the reference above. This is the citation assigned by the publisher at the time of issuing the AAM/APV. Please check the publisher's website for any updates. 


\section{Accepted Manuscript}

Research paper

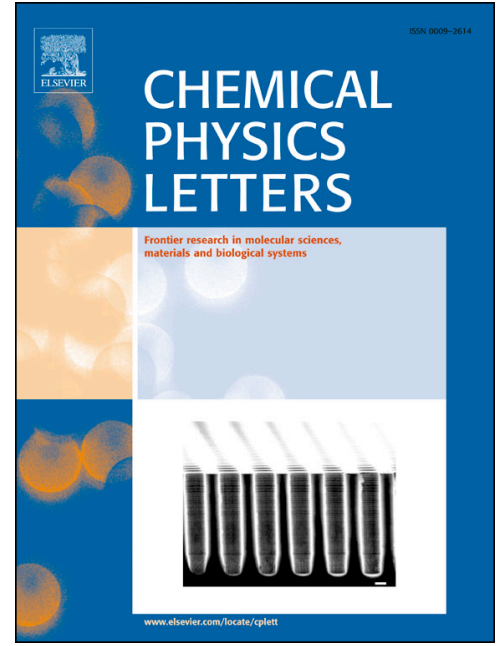

Nicole Holzmann, Leonardo Bernasconi, Kathrin M. Callaghan, Roger H.

Bisby, Anthony W. Parker

PII:

S0009-2614(17)31107-7

DOI: https://doi.org/10.1016/j.cplett.2017.12.028

Reference: CPLETT 35304

To appear in: $\quad$ Chemical Physics Letters

Received Date: $\quad 7$ November 2017

Accepted Date: $\quad 12$ December 2017

Please cite this article as: N. Holzmann, L. Bernasconi, K.M. Callaghan, R.H. Bisby, A.W. Parker, Charge Transfer in trans-Combretastatins, Chemical Physics Letters (2017), doi: https://doi.org/10.1016/j.cplett.2017.12.028

This is a PDF file of an unedited manuscript that has been accepted for publication. As a service to our customers we are providing this early version of the manuscript. The manuscript will undergo copyediting, typesetting, and review of the resulting proof before it is published in its final form. Please note that during the production process errors may be discovered which could affect the content, and all legal disclaimers that apply to the journal pertain. 


\section{Charge Transfer in trans-Combretastatins}

Nicole Holzmann ${ }^{\mathrm{a},{ }^{*}}$, Leonardo Bernasconi ${ }^{\mathrm{a}}$, Kathrin M. Callaghan ${ }^{\mathrm{a}, \mathrm{b}}$, Roger H. Bisby ${ }^{\mathrm{b}}$, Anthony W. Parker ${ }^{\mathrm{a}}$

${ }^{\mathrm{a}}$ STFC Rutherford Appleton Laboratory, Harwell Oxford, Didcot OX11 0QX, UK

${ }^{\mathrm{b}}$ School of Environment and Life Sciences, University of Salford, Salford M5 4WT, UK

* Corresponding author.

E-mail address: nicole.holzmann@stfc.ac.uk 


\begin{abstract}
The non-toxic trans isomer of combretastatin-A4 can be photoisomerised in physiological conditions to $c i s-\mathrm{CA} 4$, a potential anticancer drug. Absorption at wavelengths with high tissue penetration can be achieved by functionalization with substituents influencing the degree of charge-transfer (CT) of the $S_{1}$ state, in which the isomerisation occurs. We present a TDDFT study of the excited state properties of a series of substituted combretastatins with various degrees of CT character. Increasing the CT character determines a redshift of absorption and an intensity enhancement, but it disfavours the isomerisation. An appropriate choice of substituents is therefore required to achieve optimal isomerisation conditions.
\end{abstract}

Keywords: TDDFT, charge transfer, combretastatin, phototherapy, absorption, fluorescence 


\section{Introduction}

A major problem of chemotherapeutic cancer treatment is the severe short- and long-term side-effects that significantly influence patients' health and quality of life [1,2]. The distribution of cancer drugs throughout the whole body and the similarity of cancer cells to many normal somatic cells lead to an unwanted inhibition of numerous healthy cells in the patients' body. In recent years many attempts have been undertaken to localize cancer therapy [3]. One approach is Photodynamic Therapy (PDT) that is based on the photoexcitation of a photosensitizing drug at the tumour site inducing the generation of cell damaging singlet oxygen [4]. In previous work, we described an oxygen independent alternative to the photosensitizers utilised in PDT: the functionalised stilbene derivative Combretastatin A4 (CA4) [5]. This molecule in its cis isomer was first isolated in 1982 from the bark of the African bush willow by Pettit [6] and is known to effectively disrupt tubulin polymerisation and thus the formation of tumoral vasculature [7]. However, cis combretastatin exhibited severe side effects when tested in initial clinical trials, which has so far prevented its application in cancer therapy [8,9]. On the other hand the trans isomer, whilst considerably less toxic $\left(\mathrm{IC}_{50}\right.$ (trans) $=30 \mu \mathrm{M}$ against $\mathrm{K} 562$ cells [10]), can be photoisomerised to the cytotoxic cis conformer $\left(\mathrm{IC}_{50}(\right.$ cis $)=1-3 \mathrm{nM}$ against $\mathrm{P} 388$ [11], K562 $[10,12,13]$, and HUVEC [12] cells) by one-photon excitation at wavelengths around $340 \mathrm{~nm}$ [14]. Longer and readily tissue penetrating wavelengths in the red or near-infrared region of 600 to $900 \mathrm{~nm}$ can be achieved applying two- or three-photon excitation (2/3PE) to these systems [15]. Although the use of red and near infrared wavelengths provides greater tissue penetration, absorption cross sections are considerably reduced. For instance, the 2PE absorption cross section $\sigma_{2}$ of E-CA4 amounts to $c a .2 \times 10^{-50} \mathrm{~cm}^{4} \mathrm{~s}_{\text {photon }}{ }^{-1}$ at $625 \mathrm{~nm}$ [16], compared with the 1PE CA4 value of $1.32 \times 10^{-16} \mathrm{~cm}^{2}$ at $326 \mathrm{~nm}$ in ethanol [17]. To overcome this restriction and increase the $2 \mathrm{PE}$ cross section we propose here the addition of an electron donor group on one phenyl ring and an acceptor group on the second ring, to promote the appearance of low-lying intramolecular charge transfer (ICT) states. Redshift of the absorption and fluorescence spectra has been observed for combretastatins [18]. Based on previous experimental work on combretastatins [14-18], we present a theoretical study of the absorption and fluorescence spectra of trans stilbene derivatives with negligible or significant intramolecular CT character. We aim to clarify the observed dependence of the absorption/fluorescence wavelengths and of the tendency of the $S_{1}$ structure to isomerise on 
the CT extent in these compounds, in order to provide guidelines for the development of new photo-isomerisable cancer drug candidates. 


\section{Materials and Methods}

Absorption and fluorescence spectra of the combretastatins were measured using a PerkinElmer Lambda 25 or a Lambda 950 UV/vis spectrophotometer giving a $1 \mathrm{~nm}$ resolution. Steady state fluorescence emission measurements were carried out on a Jobin Yvon Horiba Fluoromax-3 using the spectral correction curves supplied by the manufacturer. Solvents were spectrophotometric or higher grade and used as supplied.

Theoretical calculations were carried out using the NWChem6.6 program package [19]. Ground state optimised structures were obtained using density functional theory (DFT) at the B3LYP [20,21]/def2-TZVPP [22] level of theory. Stationary points were characterized as minima by calculating the Hessian matrix analytically. For vertical excitations and excited state optimisations, the time-dependent density functional theory (TDDFT) method was applied using the standard matrix formulation $[23,24]$ with the long-range corrected CAMB3LYP functional [25], which is known to typically yield accurate CT excitation energies in molecular systems [26,27]. For the excited state optimisation the Davidson's trial vector algorithm [28] was used as implemented in NWChem for the first singlet excited state $\left(S_{1}\right)$, which corresponds to the promotion of one electron from the HOMO to the LUMO. For absorption and fluorescence spectra, vertical excitation energy calculations from the ground state optimised structure (absorption, excitation from $S_{0}$ to $S_{1}$ ) and excited state optimised structure (fluorescence, de-excitation from $S_{1}$ to $S_{0}$ ) were performed by including the 50 lowest excited states. Deformation densities and CT properties were obtained by subtracting the excited state and ground state densities [29,30] obtained from single point calculations on the ground state geometries at the CAM-B3LYP/def2-SVP [22] level of theory using the Gaussian09 [31] program suite. The "COnductor-like Screening MOdel" (COSMO) as implemented in NWChem [32,33] was used to describe the effect of seven different solvents with dielectric constants at $\mathrm{T}=20{ }^{\circ} \mathrm{C}$ [34] for the ground state optimisations (B3LYP/def2TZVPP), absorption spectra calculations (CAM-B3LYP/def2-TZVPP) and for the excited state optimisations and fluorescence calculations (CAM-B3LYP/def2-SVP). 


\section{Results and Discussion}

1. Choice of Test Set and their optimised Structures

Our considered test set of trans stilbene derivatives is depicted in Scheme 1. Apart from combretastatin A4 $(\mathrm{CA} 4, \mathbf{1})$ we included a second non-CT molecule, CA4F (2) where the hydroxyl group of $\mathbf{1}$ is substituted by fluorine. Combretastatin $3(\mathrm{CA} 4 \mathrm{CN})$ contains an electron withdrawing nitrile group in para position of the aromatic ring II. With the already present $\pi$-electron donation methoxy groups on the opposite aromatic ring $\mathbf{I}$ and the separating conjugated $\pi$ electron system, $\mathbf{3}$ is expected to have significant CT character following excitation. Excited state intramolecular CT in $\mathbf{3}$ and related compounds is confirmed by the considerably larger Stokes' shift between absorption and fluorescence maxima in polar solvents compared to $\mathbf{1}$ [17,35]. For comparison, we also considered a derivative with even stronger CT character, 4-amino-4'-cyano stilbene 4 (ACS). Distances $\left(\mathrm{d}_{\mathrm{A}}, \mathrm{d}_{\mathrm{B}}, \mathrm{d}_{\mathrm{C}}\right)$ and dihedral angles $\left(\theta_{\mathrm{A}}, \theta_{\mathrm{B}}, \theta_{\mathrm{C}}\right)$ of the three vinyl $\mathrm{C}=\mathrm{C}$ and $\mathrm{C}-\mathrm{C}$ bonds are given in Table 1 for optimised gas phase ground state $\left(\mathrm{S}_{0}\right)$ structures (DFT, B3LYP/ and CAMB3LYP/def2-TZVPP) and excited state $\left(\mathrm{S}_{1}\right)$ structures (TDDFT, CAM-B3LYP/def2-TZVPP) of 1 to 4 . Differences in bond lengths between $S_{0}$ structures calculated with the B3LYP functional and the long range corrected CAM-B3LYP are minor. In all cases bond lengths $\mathrm{d}_{\mathrm{A}}$, $d_{B}$ and $d_{C}$ are slightly shorter than the reported bond lengths in ground state calculations of trans-stilbene with CASSCF $\left(\mathrm{d}_{\mathrm{A}} / \mathrm{d}_{\mathrm{C}}=1.476 \AA \mathrm{d}_{\mathrm{B}}=1.350 \AA\right), \operatorname{MP} 2\left(\mathrm{~d}_{\mathrm{A}} / \mathrm{d}_{\mathrm{C}}=1.471 \AA, \mathrm{d}_{\mathrm{B}}=\right.$ $1.357 \AA$ ) and DFT B3LYP $\left(\mathrm{d}_{\mathrm{A}} / \mathrm{d}_{\mathrm{C}}=1.466 \AA, \mathrm{d}_{\mathrm{B}}=1.349 \AA\right.$ ) [36], while for respective values from similar TDDFT VWN/BP86 calculations $\left(\mathrm{d}_{\mathrm{A}} / \mathrm{d}_{\mathrm{C}}=1.463 \AA, \mathrm{d}_{\mathrm{B}}=1.353 \AA\right.$ ) [37] the alkyl C-C bonds $d_{A}$ and $d_{C}$ are shorter. Comparison with crystallographic data of CA4 with a tertbutyldimethylsilyl (TBS) protecting group in hydroxyl position [38] and with 4dimethylamino-4'-cyano stilbene (DCS) [39] shows reasonable agreement with respect to the bond distances, with the largest deviation from the experimental data $(0.06 \AA)$ observed for bond C of ACS/DCS (Scheme 1). Small deviations can be observed for the dihedral angles, which for bonds $\mathrm{A}$ and $\mathrm{C}$ might be caused by the shallow dihedral rotation potential, also observed in stilbene [40]. After excitation to the $S_{1}$ state, the bond distances and the dihedral angles relax similarly for all considered derivatives: the vinyl double bond length B increases while the connecting single bond lengths $\mathrm{A}$ and $\mathrm{C}$ shorten. Again, this reflects the changes in bond lengths of trans-stilbene on the $\mathrm{S}_{1}$ surface with $\mathrm{d}_{\mathrm{A}} / \mathrm{d}_{\mathrm{C}}=1.401 \AA$ and $\mathrm{d}_{\mathrm{B}}=1.439 \AA$ (TDDFT, VWN/BP86) [37]. Thes increase/decrease in bond lengths is reflected in the frontier orbital shape (Figure 1 for 3, see Supporting Material Figure S1 for 1 - 4), where the 
HOMO has $\pi$ bonding character with respect to the vinyl $\mathrm{C}=\mathrm{C}$ bond $\mathrm{B}$ and of $\pi$ anti-bonding character with respect to bonds A and C. The situation in the LUMO is reversed and, on promotion of one electron from the HOMO to the LUMO, the double bond character of $\mathrm{B}$ is reduced whereas the order of bonds $\mathrm{A}$ and $\mathrm{C}$ increases. Theoretical studies on the topology of the electron density of trans-stilbene confirm these findings showing decreased electron density and a reduction in local charge concentration in the $\mathrm{C}=\mathrm{C}$ vinyl bond [41]. Dynamical simulations for the photoisomerisation of trans-stilbene induced by a femtosecond-scale laser pulse indicate that the excitation weakens the central $\mathrm{C}=\mathrm{C}$ bond, but also induces vibrations of this bond, which mechanistically lead to energy distribution and rotation [42]. Consequently, for the desired isomerisation to the cis isomer and thus for rotation around bond $\mathrm{B}$, the loss of double bond character is crucial, as the $\pi$ orbital overlap of the rotational fragments in the molecular HOMO prevents this rotation. Furthermore, the planarity of the $\mathrm{C}_{\mathrm{ar}}-\mathrm{C}=\mathrm{C}-\mathrm{C}_{\mathrm{ar}}$ moiety is slightly sacrificed by a dihedral angle change of bond $\mathrm{B}$ of less than $2^{\circ}$ for the compounds 1 to 3 while the dihedral angles of bonds $\mathrm{A}$ and $\mathrm{C}$ change by about the same amount to approach $180^{\circ}$. Overall the changes in conformation are minor, which is consistent with rotational coherence spectroscopy studies of the CT stilbene derivative 4dimethylamino-4'-cyanostilbene (DCS) [43]. However, it should be noted that the changes in bond distances and dihedral angles on excitation are less pronounced in the two CT compounds 3 and 4 (e.g. increase of distance in bond B of 0.067 and $0.063 \AA$ ) than in their non-CT derivatives 1 and 2 (0.075 and $0.074 \AA$, respectively), while the reported $\mathrm{C}=\mathrm{C}$ bond elongation in trans-stilbene (which due to its symmetry cannot have any CT character) with $0.086 \AA$ (TDDFT VWN/BP86) [37] is even larger. This indicates that the loss in double bond character is smaller in the CT molecules compared with their non-CT analogues. The reason for this becomes apparent when taking a closer look at the LUMO of CA4CN (Figure 1): while the population of the LUMO on excitation increases the anti-bonding character of bond $\mathrm{B}$ in all stilbene derivatives, it is only for the CT molecules that bond A shows an increased electron localisation on the central (vinyl) carbon atom. Electron density is thus pulled towards the vinyl bond elevating its double bond character slightly. This effect is due to the strong electron withdrawing effect of the substituents on ring II, which is absent in the non$\mathrm{CT}$ analogues. As the isomerisation process is linked to the loss in double bond character, this indicates that the isomerisation is less favourable in combretastatins derivatives with higher $\mathrm{S}_{1} \mathrm{CT}$ character. 


\section{Quantification of CT Character}

To quantify the degree of CT, we compared the $S_{0}$ and $S_{1}$ states electron densities for the ground state structures of $\mathbf{1}$ to $\mathbf{4}$. Using the approach of Jaquemin et al. [29,44], we obtained the amount of transferred charge, the CT distance and the CT dipole by subtracting the ground state electron density $\rho^{G S}(\boldsymbol{r})$ from the excited state density $\rho^{E S}(\boldsymbol{r})$ and by calculating the photo-induced shift in the barycentre of the electronic charge density for the ground and CT states (for full results see Supplementary Material),

$$
\Delta \rho(\boldsymbol{r})=\rho^{E S}(\boldsymbol{r})-\rho^{G S}(\boldsymbol{r})
$$

Both the CT distance and the CT dipole are considerably lower in the non-CT combretastatins $1(0.27 \AA, 0.5$ Debye) and 2 (0.49 A, 0.9 Debye) than in their CT analogues 3 (2.52 $\AA$, 5.6 Debye) and 4 (2.89 ̊̊, 6.5 Debye). The resulting order of CT $(\mathbf{1}<\mathbf{2}<<3<)$ corresponds qualitatively to the trend of structure changes on excitation, which are largest for 1 and smallest for 4. Experimentally, the dipole moment difference between the excited and ground states $\left(\Delta \mu=\mu_{\mathrm{es}}-\mu_{\mathrm{gs}}\right)$ can be assessed via the widely used Lippert-Mataga $[45,46]$ model (equation 2) relating the Stokes' shift $\left(v_{A}-v_{F}\right)$ between maxima of the absorption and fluorescence spectra to the solvent parameter $\Delta \mathrm{f}$ (equation 3 ) for the range of solvents of varying polarity in Table 2 .

$$
\begin{aligned}
& v_{A}-v_{F}=\frac{2}{h c} \cdot \frac{\left(\mu_{e s}-\mu_{g s}\right)^{2}}{a^{3}} \cdot \Delta f \\
& \Delta \mathrm{f}=\left\{\frac{\varepsilon-1}{2 \varepsilon+1}-\frac{\mathrm{n}^{2}-1}{2 \mathrm{n}^{2}+1}\right\}
\end{aligned}
$$

With the radius of the solvent cavity containing the fluorophore (a) set to $5.92 \AA$ for the Onsager cavity volume as previously suggested by Anstead et al. [47] and to allow comparison with data for comparable compounds [35], the results show that $\Delta \mu$ for $\mathbf{3}$ is 14.4 \pm 3.5 Debye, whereas that for 1 is only $5.1 \pm 3.9$ Debye. Qualitatively, this is in good agreement with our calculated results. The difference in electron densities depicted in Figure 2 (charge density flow on excitation from red to blue/gray to white) all show the earlier described relocation from electrons of the vinyl $\mathrm{C}=\mathrm{C}$ double bond into the $\mathrm{C}-\mathrm{C}_{\mathrm{ar}}$ single bonds. Additionally it can be seen clearly that in the CT compounds $\mathbf{3}$ and $\mathbf{4}$ an electron density shift from the electron pushing ring I (predominantly red/gray areas) into the electron accepting ring II (predominantly blue/white areas) takes place on excitation. 


\section{Calculated Absorption and Fluorescence Spectra}

The dominant peaks in the absorption and fluorescence spectra of the gas-phase stilbene derivatives 1 to $\mathbf{4}$ calculated at the CAM-B3LYP/def2-TZVPP level are shown in Figure 3 and they correspond to the singlet excitation from the HOMO to the LUMO of the ground state structures and the respective de-excitation for the $S_{1}$ state optimised structures (for complete calculated spectra see Supporting Material Figure S2 and Tables S1 to S8). The agreement with the experimental absorption peak location of combretastatins 1 to $\mathbf{3}$ in the non-polar solvent hexane is reasonably good with a slight underestimation (10 to $16 \mathrm{~nm}$ ) of the calculated values compared to experiment. The redshift in absorption for CT compound 3 relative to $\mathbf{1}$ is well reproduced (differences between TDDFT predictions and experiment are of approximately $10 \mathrm{~nm}$ ). Considering also 4, the previously described trend of CT character is reflected in the absorption peak redshift with a minor shift from the non-CT compound $\mathbf{1}$ to its analogue $\mathbf{2}$ while the shifts become more significant with increased CT character in $\mathbf{3}$ and 4. Both excitation wavelengths for the non-CT $\mathbf{1}$ and $\mathbf{2}$ are within the range of different reported TDDFT results of 311 to $321 \mathrm{~nm}$ for the vertical excitation of trans-stilbene [36,41] while the respective wavelengths of the CT derivatives are higher. This confirms the assumption that smaller excitation energies are needed in stilbene derivatives with increased intramolecular CT on promotion to $S_{1}$. The quality of the calculated gas phase fluorescence spectra relative to experimental measurements in hexane is slightly inferior (differences are of the order of $27 \mathrm{~nm}$ ) for all three combretastatins. The increased Stokes' shift in more polar solvents for compounds with higher CT character is however well reproduced. Both the relative locations of the fluorescence peaks and the Stokes shift do not mirror the calculated extent of CT. Oscillator strengths [48] for the main HOMO $\rightarrow$ LUMO excitation peak from our calculations are again smaller values for the non-CT compounds (1.14 for $\mathbf{1}$ and 1.11 for 2) and increase with CT character to 1.20 for 3 and 1.24 for $\mathbf{4}$, confirming the experimentally observed increased in the $2 \mathrm{PE}$ absorption cross section for CA4CN [17].

Under the assumption that the shape of the isomerisation coordinate for $\mathbf{1}$ to $\mathbf{4}$ is similar to that of stilbene [40,49], the crucial factor affecting the trans to cis photoisomerisation is the height of the potential barrier that connects the $S_{1}$ local minimum at a dihedral angle for bond $\mathrm{B}$ of around $180^{\circ}$ with a minimum energy twisted conformation. For stilbene the latter is found to be at a dihedral angle of $90^{\circ}$ and located exactly above the maximum of the $\mathrm{S}_{0}$ isomerisation coordinate (conical intersection), resulting in a 50/50 conversion to the trans and $c$ is isomer after de-excitation. The calculated relaxation energies (the difference between 
the energy of the excited state optimised structure on the $S_{1}$ surface and the same structure on the ground state surface, Supporting Information, Table S9) on the $S_{1}$ energy surface after absorption and structure relaxation are slightly higher for the non-CT compounds 1 (7.2 $\mathrm{kcal} / \mathrm{mol})$ and $2(7.5 \mathrm{kcal} / \mathrm{mol})$ than for the CT analogues $3(6.8 \mathrm{kcal} / \mathrm{mol})$ and $4(5.4$ $\mathrm{kcal} / \mathrm{mol}$ ). This indicates that the evolution over the barrier might be favoured for the non-CT combretastatins, if the barrier height of stilbene is conserved for its derivatives. However, introduction of CT character may also influence the barrier height and balance this effect. It is also conceivable that $\mathrm{CT}$ character shifts the relative positions of the $\mathrm{S}_{1}$ twisted minimum and the $\mathrm{S}_{0}$ trans/cis transition state leading to an increase or decrease of the isomerisation yield with respect to the excitation of the trans isomers. To fully assess these aspects, an examination of the $S_{1}$ potential energy surface topology is necessary, and a detailed TDDFT study of the photo-induced isomerisation will be presented elsewhere [50].

\section{Solvent Effects}

We carried out one photon absorption and fluorescence spectroscopy and TDDFT calculations in seven solvents of different polarity, namely hexane, ethyl acetate, propan-2-ol, ethanol, methanol, ethylene glycol and DMSO for the combretastatins 1 to 3. Experimental and calculated values are listed in Table 2. The influence of the solvent on the location of the combretastatin absorption peaks is negligible. In the fluorescence spectra, it is only for the non-CT compounds $\mathbf{1}$ and $\mathbf{2}$ that the peak location does not change significantly in different solvents. A clear redshift with increased solvent polarity can be observed in the fluorescence of 3 , with the peak at $414 \mathrm{~nm}$ in hexane shifting to $475 \mathrm{~nm}$ in DMSO. The calculated trend of redshift with solvent polarity is lower than experimentally observed, but it qualitatively mirrors the experimental within a range of $379 \mathrm{~nm}$ for $\mathbf{3}$ in hexane and up to $386 \mathrm{~nm}$ in methanol. Additional calculations of the fluorescence of CT compound $\mathbf{4}$ with a peak location of $384 \mathrm{~nm}$ in hexane and $392 \mathrm{~nm}$ DMSO add further evidence that the redshift with increased solvent polarity is indeed directly related to the CT character of the $S_{1}$ state. 


\section{Conclusion}

We used TDDFT calculations to study the effects of electron donor/acceptor substituent groups in a series of combretastatins of potential relevance in cancer treatment with PDT. By comparison of excited state and ground state electron densities, we showed that the CT character in the $\mathrm{S}_{1}$ excitation of the two combretastatins CA4 (1) and CA4F (2) is negligible, whereas it increases significantly for combretastatin CA4CN (3) and the stilbene derivative ACS (4). In the optically allowed $\pi \rightarrow \pi^{*}$ transition, one electron occupying the HOMO is promoted to the LUMO and both the elongation of the vinyl $\mathrm{C}=\mathrm{C}$ bond and the shape of the orbitals indicate a decrease in bond order, which is beneficial for the desired photoinduced rotation to the cis isomer. Although the changes in the geometries are minor in all cases, a more pronounced elongation of the internal $\mathrm{C}=\mathrm{C}$ double bond can be observed in the non-CT compounds, as the CT effect shifts electron density towards the vinyl bond, reducing the decrease in the double bond character of the $S_{1}$ state in $\mathbf{3}$ and $\mathbf{4}$. The dominant peak in the absorption spectra could be assigned to the HOMO $\rightarrow$ LUMO excitation and the experimentally observed redshift and increased $2 \mathrm{PE}$ absorption cross section for the CT combretastatin 3 was verified by our calculations. A further redshift in the calculated absorption spectrum of $\mathbf{4}$ confirms the assumed CT dependence of the peak energy. Relaxation energies on the $S_{1}$ surface were found to be more pronounced for the non-CT combretastatins, which indicates that the isomerisation barrier can be overcome more readily for compounds $\mathbf{1}$ and $\mathbf{2}$ if the overall barrier height is similar in all studied stilbene derivatives. Our experimental and theoretical results suggest that the absorption wavelengths, as well as the absorption cross sections, can be tuned to achieve optimal tissue penetration by enhancing the intramolecular CT character in functionalised stilbenes. These findings suggest that only though a very judicious choice of substituents, an appropriate balance of these effects can be achieved. A complete study of the photoinduced $S_{1}$ isomerisation process and of its dependence on the CT character of the excitation will be the subject of future work. 


\section{Acknowledgement}

This work was supported by STFC through a Service Level Agreement with EPSRC (grant EP/L000202) and by the STFC SCD/Facilities Programme. Calculations were carried out on the SCARF cluster at STFC Rutherford Appleton Laboratory and on the ARCHER National Supercomputing Service. 


\section{Figures and Tables}

Table 1: Optimised gas phase and experimental structure data of 1 to 4. Ground state DFT calculations were carried out with B3LYP/ and CAM-B3LYP/def2-TZVPP, excited state TDDFT calculations with CAM-B3LYP/def2-TZVPP. Distances $\mathrm{d}$ in $\AA$, dihedral angles $\theta$ in $\circ$, excited state structure data is given in italics.

\begin{tabular}{llcccccc}
\hline & $\mathrm{d}_{\mathrm{A}}$ & $\mathrm{d}_{\mathrm{B}}$ & $\mathrm{d}_{\mathrm{C}}$ & $\theta_{\mathrm{A}}$ & $\theta_{\mathrm{B}}$ & $\theta_{\mathrm{C}}$ \\
\hline $\mathbf{1}$ & B3LYP & 1.463 & 1.343 & 1.461 & 178.4 & 180.0 & 179.5 \\
& CAM-B3LYP & 1.470 & 1.341 & 1.468 & 178.5 & 180.0 & 179.5 \\
& exp. (CA4-TBS) & 1.473 & 1.319 & 1.469 & -178.5 & -177.4 & -175.5 \\
& CAM-B3LYP & 1.401 & 1.413 & 1.411 & 179.1 & 178.2 & 179.1 \\
\hline $\mathbf{2}$ & B3LYP & 1.462 & 1.342 & 1.460 & 178.7 & -179.9 & 179.5 \\
& CAM-B3LYP & 1.470 & 1.341 & 1.468 & 178.9 & -179.9 & 180.0 \\
& CAM-B3LYP & 1.410 & 1.413 & 1.408 & 179.1 & 178.2 & 179.2 \\
\hline $\mathbf{3}$ & B3LYP & 1.461 & 1.343 & 1.459 & 177.1 & 180.0 & 178.0 \\
& CAM-B3LYP & 1.469 & 1.342 & 1.468 & 177.6 & 180.0 & 178.2 \\
& CAM-B3LYP & 1.414 & 1.406 & 1.412 & 179.6 & 178.9 & 179.5 \\
\hline $\mathbf{4}$ & B3LYP & 1.454 & 1.346 & 1.458 & -179.8 & 180.0 & 180.0 \\
& CAM-B3LYP & 1.463 & 1.344 & 1.467 & -179.9 & 180.0 & 180.0 \\
& exp. (DCS) & 1.452 & 1.334 & 1.525 & -176.9 & -177.4 & 175.2 \\
& CAM-B3LYP & 1.417 & 1.404 & 1.414 & 180.0 & 180.0 & 180.0 \\
\hline
\end{tabular}


Table 2: Calculated and experimental absorption and fluorescence data (nm) in gas phase and solution. Data at CAM-B3LYP/def2-TZVPP (and CAM-B3LYP/def2-SVP in parentheses).

\begin{tabular}{lcccccccc}
\hline & \multicolumn{2}{c}{$\mathbf{1}$} & \multicolumn{2}{c}{$\mathbf{2}$} & \multicolumn{3}{c}{$\mathbf{4}$} & $\mathbf{4}$ \\
& $\varepsilon$ & Calc. & Exp. & Calc. & Exp. & Calc. & Exp. & Calc. \\
\hline Absorption & & & & & & & & \\
Gas phase & & 313 & & 315 & & 326 & & 337 \\
Hexane & 1.89 & 313 & 329 & 314 & 326 & 325 & 336 & - \\
Ethyl acetate & 6.00 & 313 & 330 & 312 & 327 & 324 & 336 & - \\
Propan-2-ol & 18.30 & 314 & 331 & 312 & 325 & 324 & 336 & - \\
Ethanol & 24.60 & 314 & 330 & 311 & 326 & 324 & 336 & - \\
Methanol & 32.60 & 314 & 329 & 312 & 325 & 324 & 336 & - \\
Ethylene glycol & 37.70 & 314 & 332 & 312 & 329 & 324 & N/A & - \\
DMSO & 47.00 & 314 & 334 & 311 & 332 & 324 & 344 & - \\
Fluorescence & & & & & & & & \\
Gas phase & & 374 & & 380 & & 388 & & 389 \\
Hexane & 1.89 & $(365)$ & 383 & $(370)$ & 379 & $(379)$ & 414 & $(384)$ \\
Ethyl acetate & 6.00 & $(365)$ & 381 & $(370)$ & 382 & $(382)$ & 445 & $(389)$ \\
Propan-2-ol & 18.30 & $(366)$ & 386 & $(370)$ & 380 & $(385)$ & 455 & $(391)$ \\
Ethanol & 24.60 & $(366)$ & 380 & $(370)$ & 380 & $(381)$ & 461 & $(391)$ \\
Methanol & 32.60 & $(366)$ & 382 & $(370)$ & 380 & $(386)$ & 469 & $(392)$ \\
Ethylene glycol & 37.70 & $(366)$ & 391 & $(370)$ & 394 & $(381)$ & 476 & $(392)$ \\
DMSO & 47.00 & $(366)$ & 390 & $(370)$ & 392 & $(383)$ & 475 & $(392)$ \\
\hline
\end{tabular}


Scheme 1: Stilbene derivatives 1 to 4 .

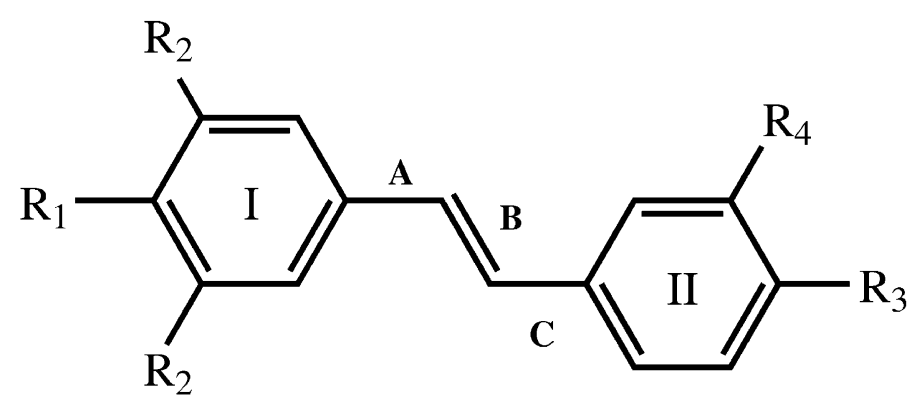

1: $\mathrm{R}_{1}=\mathrm{OMe}, \mathrm{R}_{2}=\mathrm{OMe}, \mathrm{R}_{3}=\mathrm{OMe}, \mathrm{R}_{4}=\mathrm{OH}$

2: $\mathrm{R}_{1}=\mathrm{OMe}, \mathrm{R}_{2}=\mathrm{OMe}, \mathrm{R}_{3}=\mathrm{OMe}, \mathrm{R}_{4}=\mathrm{F}$

3: $\mathrm{R}_{1}=\mathrm{OMe}, \mathrm{R}_{2}=\mathrm{OMe}, \mathrm{R}_{3}=\mathrm{CN}, \mathrm{R}_{4}=\mathrm{H}$

4: $\mathrm{R}_{1}=\mathrm{NH}_{2}, \mathrm{R}_{2}=\mathrm{H}, \mathrm{R}_{3}=\mathrm{CN}, \mathrm{R}_{4}=\mathrm{H}$

(single column image) 
Figure 1: HOMO and LUMO orbital of $\mathbf{3}$ calculated with CAM-B3LYP/def2-TZVPP.

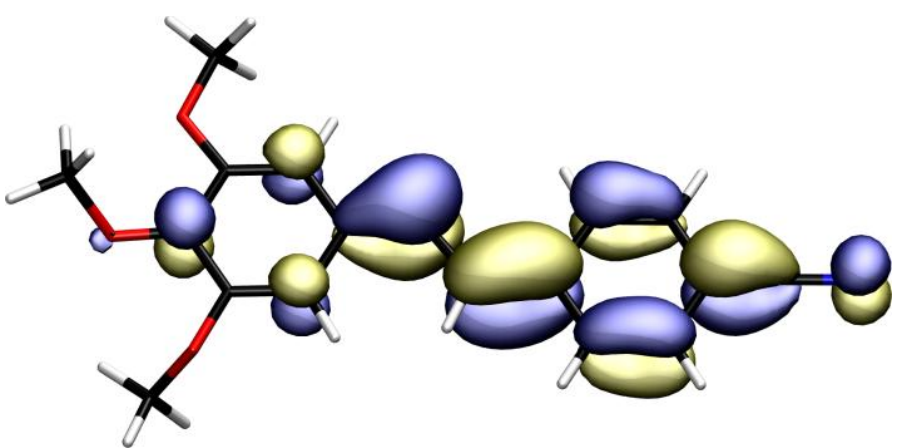

LUMO

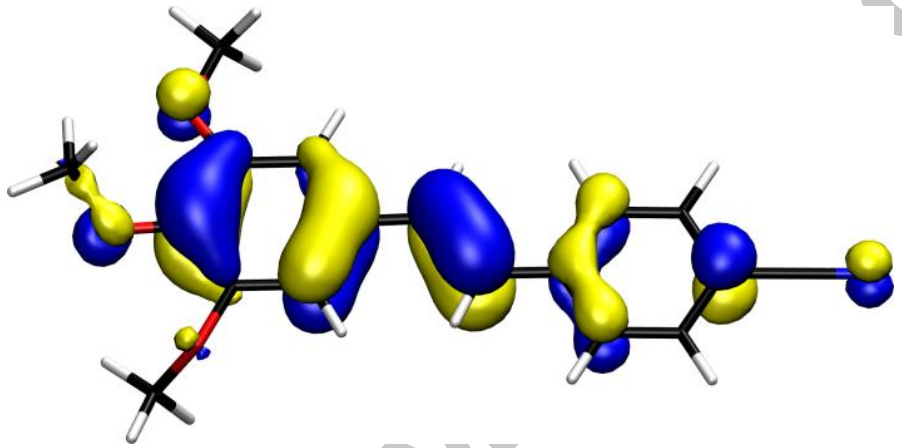

HOMO

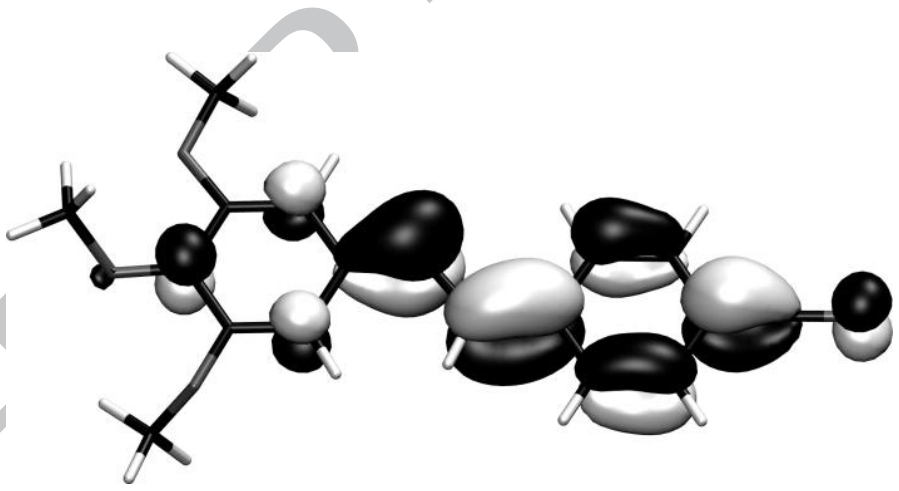

LUMO

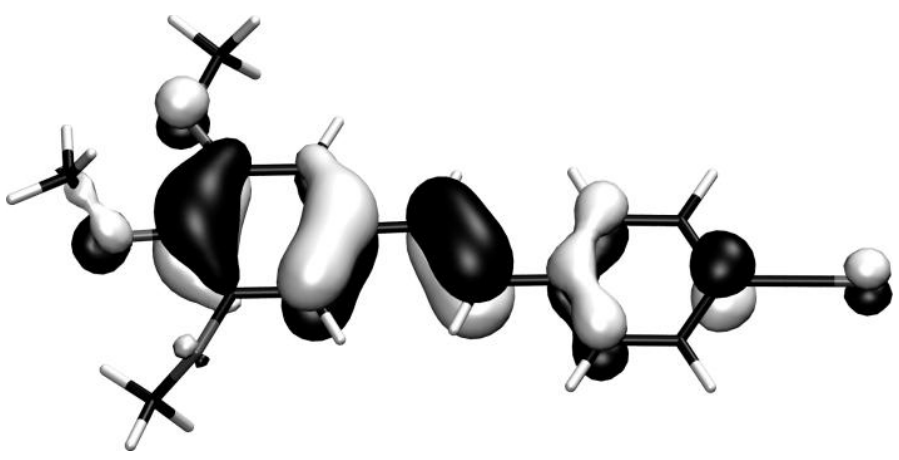

HOMO

(single column image. Top: Color for online, bottom: black and white for print) 
Figure 2: Difference densities of excited and ground state electron densities calculated with CAM-B3LYP/def2-SVP. Areas of electron depletion are shown in red/gray and areas of electron accumulation are shown in blue/white.
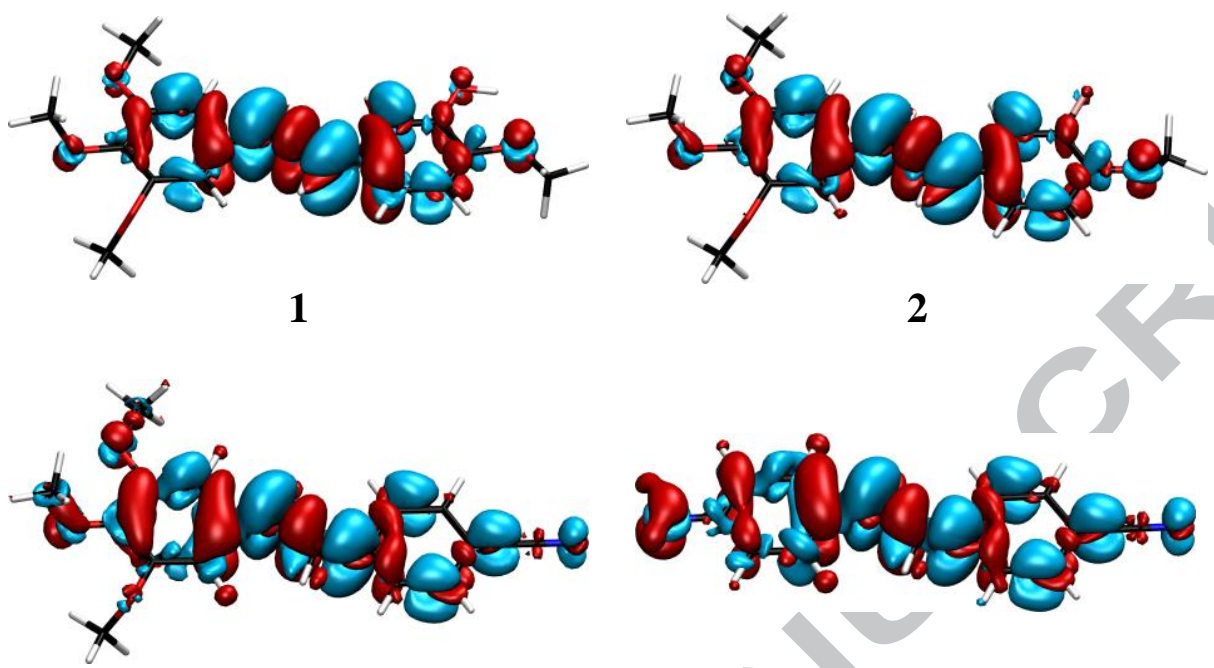

3

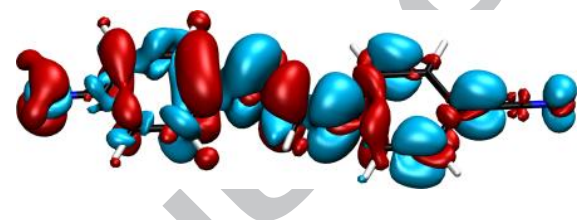

4

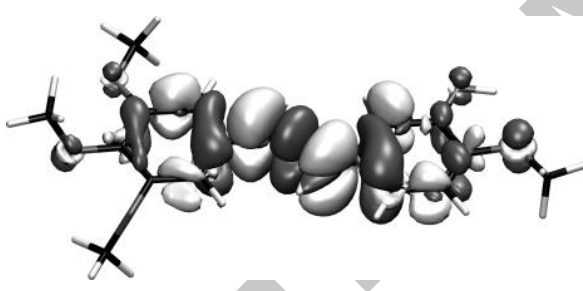

1
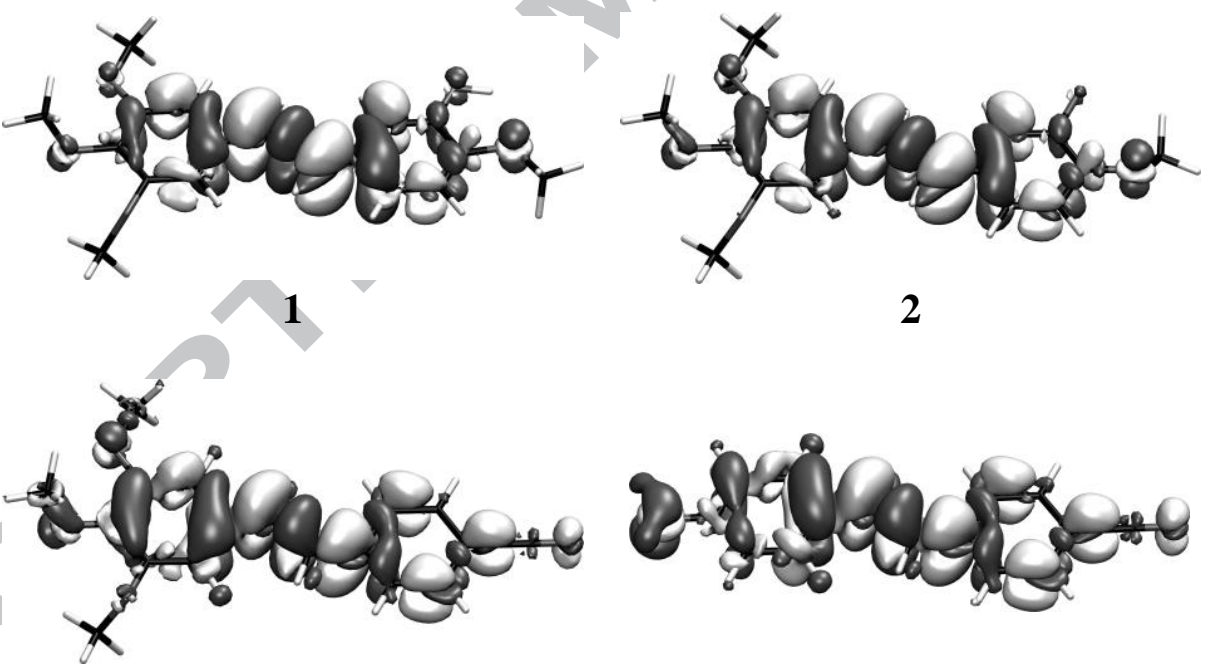

3

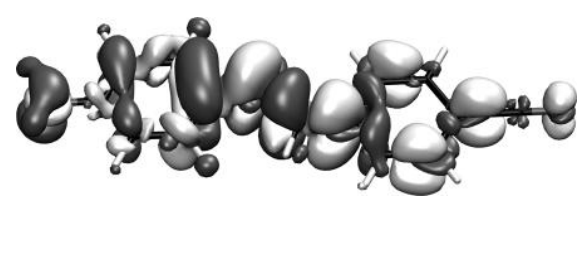

4

(1.5 column image. Top: Color for online, bottom: black and white for print) 
Figure 3: Absorption and Fluorescence (light colours/gray) of compounds $\mathbf{1}$ to $\mathbf{4}$ calculated at CAM-B3LYP/def2-TZVPP.
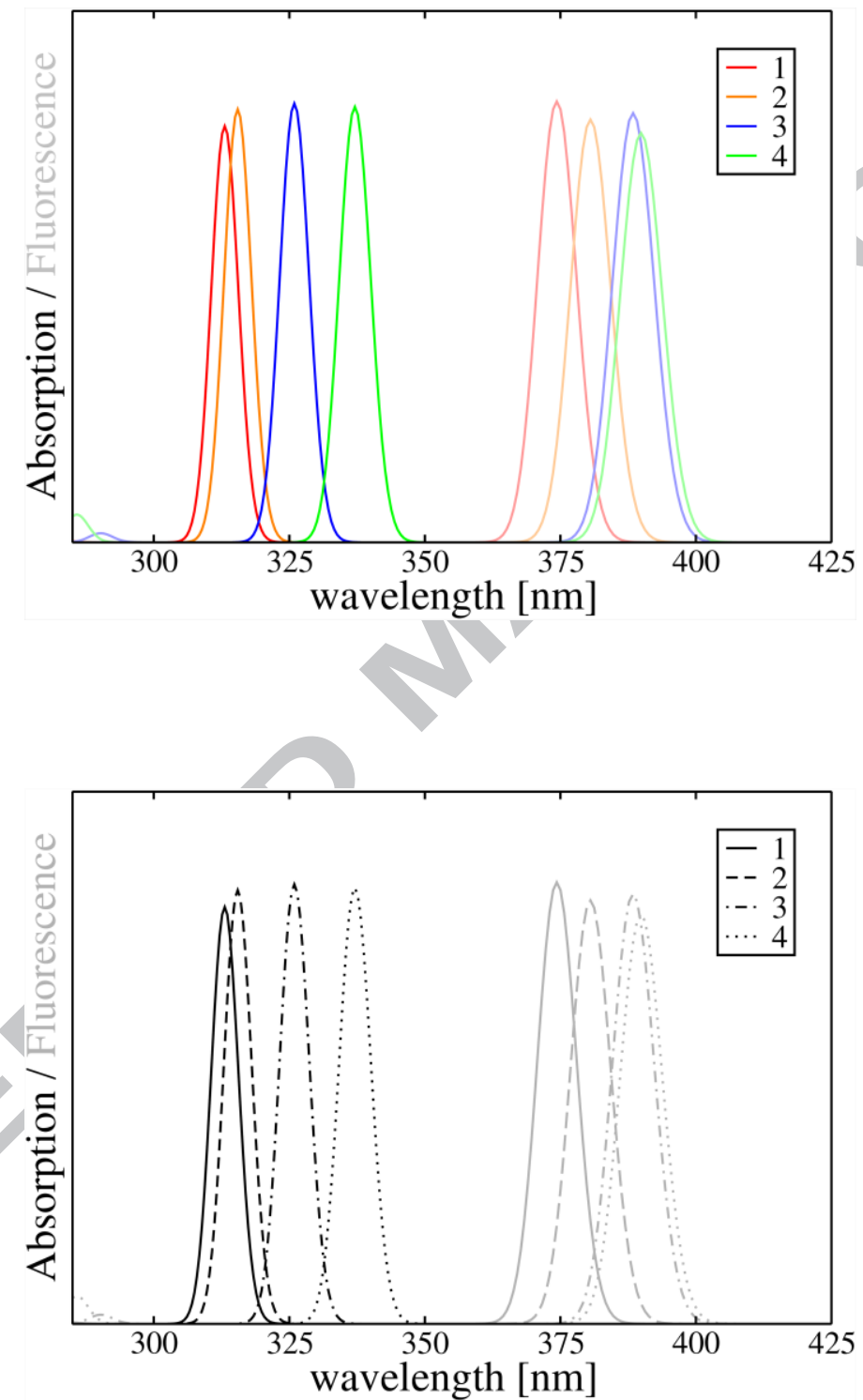

(single column image. Top: Color for online, bottom: black and white for print) 
[1] L. Y. Ramirez, S. E. Huestis, T. Y. Yap, S. Zyzanski, D. Drotar and E. Kodish, "Potential chemotherapy side effects: what do oncologists tell parents?," Pediatric blood \& cancer, vol. 52, no. 4, pp. 497-502, 2009.

[2] B. Mlineritsch, "Is Higher Efficacy Always at the Price of More Side Effects during Chemotherapy?," Breast Care, vol. 4, no. 3, pp. 162-165, 2009.

[3] K. Krukiewicz and J. K. Zak, "Biomaterial-based regional chemotherapy: Local anticancer drug delivery to enhance chemotherapy and minimize its side-effects," Materials Science and Engineering: C, vol. 62, pp. 927-942, 2016.

[4] P. Agostinis, K. Berg, K. A. Cengel, T. H. Foster, A. W. Girotti, S. O. Gollnick, S. M. Hahn, M. R. Hamblin, A. Juzeniene, D. Kessel and others, "Photodynamic therapy of cancer: an update," CA: a cancer journal for clinicians, vol. 61, no. 4, pp. 250-281, 2011.

[5] K. M. Scherer, R. H. Bisby, S. W. Botchway, A. W. Parker, "New Approaches to Photodynamic Therapy from Types I, II and III to Type IV Using One or More Photons," Anti-Cancer Agents in Medicinal Chemistry, vol. 17 , no. 2, pp. 171-189, 2017.

[6] G. R. Pettit, G. M. Cragg, D. L. Herald, J. M. Schmidt and P. Lohavanijaya, "Isolation and structure of combretastatin," Canadian Journal of Chemistry, vol. 60, no. 11, pp. 13741376, 1982.

[7] G. C. Tron, T. Pirali, G. Sorba, F. Pagliai, S. Busacca and A. A. Genazzani, "Medicinal chemistry of combretastatin A4: present and future directions," Journal of medicinal chemistry, vol. 49, no. 11, pp. 3033-3044, 2006.

[8] G. J. S. Rustin, S. M. Galbraith, H. Anderson, M. Stratford, L. K. Folkes, L. Sena, L. Gumbrell and P. M. Price, "Phase I clinical trial of weekly combretastatin A4 phosphate: clinical and pharmacokinetic results," Journal of clinical oncology, vol. 21, no. 15, pp. 28152822, 2003.

[9] G. J. Rustin, G. Shreeves, P. D. Nathan, A. Gaya, T. S. Ganesan, D. Wang, J. Boxall, L. Poupard, D. J. Chaplin, M. R. L. Stratford and others, "A Phase Ib trial of CA4P (combretastatin A-4 phosphate), carboplatin, and paclitaxel in patients with advanced cancer," British journal of cancer, vol. 102, no. 9, pp. 1355-1360, 2010. 
[10] L. A. Hepworth, New procedures for the photoactivation of anticancer photodrugs. (unpublished), Manchester: University of Manchester Institute of Science and Technology, 2000.

[11] N. J. Lawrence, D. Rennison, M. Woo, A. T. McGown and J. A. Hadfield, "Antimitotic and cell growth inhibitory properties of combretastatin A-4-like ethers," Bioorganic \& medicinal chemistry letters, vol. 11, no. 1, pp. 51-54, 2001.

[12] K. Gaukroger, J. A. Hadfield, N. J. Lawrence, S. Nolan and A. T. McGown, "Structural requirements for the interaction of combretastatins with tubulin: how important is the trimethoxy unit?," Organic \& biomolecular chemistry, vol. 1, no. 17, pp. 3033-3037, 2003.

[13] N. J. Lawrence, L. A. Hepworth, D. Rennison, A. T. McGown and J. A. Hadfield, "Synthesis and anticancer activity of fluorinated analogues of combretastatin A-4," Journal of fluorine chemistry, vol. 123, no. 1, pp. 101-108, 2003.

[14] R. H. Bisby, S. W. Botchway, G. M. Greetham, J. A. Hadfield, A. T. McGown, A. W. Parker, K. M. Scherer and M. Towrie, "Time-resolved nanosecond fluorescence lifetime imaging and picosecond infrared spectroscopy of combretastatin A-4 in solution and in cellular systems." Measurement Science and Technology, vol. 23, no. 8, p. 084001, 2012. [15] K. M. Scherer, R. H. Bisby, S. W. Botchway, G. M. Greetham, J. A. Hadfield, A. W. Parker and M. Towrie, "Spectroscopy and fluorescence lifetime imaging in live cells of a cyano-substituted combretastatin," Biomedical Spectroscopy and Imaging, vol. 3, no. 3, pp. 211-218, 2014.

[16] K. M. Scherer, R. H. Bisby, S. W. Botchway, J. A. Hadfield, and A. W. Parker, "Anticancer phototherapy of E-combretastatins by two-photon-induces isomerisation," Journal of biomedical optics, vol. 20, no. 5, pp. 051004, 2015.

[17] K. M. Scherer, "Two-photon microscopy of E-combretastatin uptake and activation in live mammalian cells," PhD Thesis, University of Salford (2012).

[18] K. M. Scherer, R. H. Bisby, S. W. Botchway, J. A. Hadfield, J. W. Haycock and A. W. Parker, "Three-dimensional imaging and uptake of the anticancer drug combretastatin in cell spheroids and photoisomerization in gels with multiphoton excitation," Journal of biomedical optics, vol. 20, no. 7, pp. 78003-78003, 2015. 
[19] M. Valiev, E. J. Bylaska, N. Govind, K. Kowalski, T. P. Straatsma, H. J. J. Van Dam, D. Wang, J. Nieplocha, E. Apra, T. L. Windus and others, "NWChem: a comprehensive and scalable open-source solution for large scale molecular simulations," Computer Physics Communications, vol. 181, no. 9, pp. 1477-1489, 2010.

[20] A. D. Becke, "Density-functional thermochemistry. III. The role of exact exchange," The Journal of chemical physics, vol. 98, no. 7, pp. 5648-5652, 1993.

[21] C. Lee, W. Yang and R. G. Parr, "Development of the Colle-Salvetti correlation-energy formula into a functional of the electron density," Physical review B, vol. 37, no. 2, p. 785, 1988.

[22] F. Weigend and R. Ahlrichs, "Balanced basis sets of split valence, triple zeta valence and quadruple zeta valence quality for $\mathrm{H}$ to $\mathrm{Rn}$ : design and assessment of accuracy," Physical Chemistry Chemical Physics, vol. 7, no. 18, pp. 3297-3305, 2005.

[23] A. Dreuw and M. Head-Gordon, "Single-reference ab initio methods for the calculation of excited states of large molecules," Chemical reviews, vol. 105, no. 11, pp. 4009-4037, 2005 .

[24] M. E. Casida, in Recent Developments and Applications of Modern Density Functional Theory, Theoretical and Computational Chemistry, edited by J. M. Seminario Elsevier, Amsterdam, 1996 , Vol. 4.

[25] T. Yanai, D. P. Tew and N. C. Handy, "A new hybrid exchange--correlation functional using the Coulomb-attenuating method (CAM-B3LYP)," Chemical Physics Letters, vol. 393, no. 1, pp. 51-57, 2004.

[26] A. Charaf-Eddin, A. Planchat, B. Mennucci, C. Adamo, D. Jacquemin, "Choosing a Functional for Computing Absorption and Fluorescence Band Shapes with TD-DFT," Journal of Chemical Theory and Computation, no. 9, pp. 2749-2760, 2013.

[27] M. Pastore, E. Mosconi, F. De Angelis, M. Grätzel, “A Computational Investigation of Organic Dyes for Dye-Sensitized Solar Cells: Benchmark, Strategies, and Open Issues," The Journal of Physical Chemistry C, vol. 114, pp. 7205-7212, 2010.

[28] E. R. Davidson, "The Iterative Calculation of a Few of the Lowest Eigenvalues and Corresponding Eigenvectors of Large Real-Symmetric Matrices,” Journal of Computational Physics, vol. 17, no. 1, pp. 87-94, 1975. 
[29] T. Le Bahers, C. Adamo and I. Ciofini, "A qualitative index of spatial extent in chargetransfer excitations," Journal of Chemical Theory and Computation, vol. 7, no. 8, pp. 24982506, 2011.

[30] D. Jacquemin, T. Le Bahers, C. Adamo and I. Ciofini, "What is the "best" atomic charge model to describe through-space charge-transfer excitations?," Physical Chemistry Chemical Physics, vol. 14, no. 16, pp. 5383-5388, 2012.

[31] M. J. Frisch, G. W. Trucks, H. B. Schlegel, G. E. Scuseria, M. A. Robb, J. R. Cheeseman, G. Scalmani, V. Barone, G. A. Petersson, H. Nakatsuji, X. Li, M. Caricato, A. Marenich, J. Bloino, B. G. Janesko, R. Gomperts, B. Mennucci, H. P. Hratchian, J. V. Ortiz, A. F. Izmaylov, J. L. Sonnenberg, D. Williams-Young, F. Ding, F. Lipparini, F. Egidi, J. Goings, B. Peng, A. Petrone, T. Henderson, D. Ranasinghe, V. G. Zakrzewski, J. Gao, N. Rega, G. Zheng, W. Liang, M. Hada, M. Ehara, K. Toyota, R. Fukuda, J. Hasegawa, M. Ishida, T. Nakajima, Y. Honda, O. Kitao, H. Nakai, T. Vreven, K. Throssell, J. A. Montgomery, Jr., J. E. Peralta, F. Ogliaro, M. Bearpark, J. J. Heyd, E. Brothers, K. N. Kudin, V. N. Staroverov, T. Keith, R. Kobayashi, J. Normand, K. Raghavachari, A. Rendell, J. C. Burant, S. S. Iyengar, J. Tomasi, M. Cossi, J. M. Millam, M. Klene, C. Adamo, R. Cammi, J. W. Ochterski, R. L. Martin, K. Morokuma, O. Farkas, J. B. Foresman, and D. J. Fox, Gaussian09, Gaussian Inc., Wallingford CT, 2016.

[32] A. Klamt and G. J. G. J. Schürmann, "COSMO: a new approach to dielectric screening in solvents with explicit expressions for the screening energy and its gradient," Journal of the Chemical Society, Perkin Transactions 2, no. 5, pp. 799-805, 1993.

[33] D. M. York and M. Karplus, "A smooth solvation potential based on the conductor-like screening model," The Journal of Physical Chemistry A, vol. 103, no. 50, pp. 11060-11079, 1999.

[34] D. R. Lide, Ed., CRC Handbook of Chemistry and Physics, CRC Press, 2006.

[35] A. K. Singh, S. Kanvah, "Photophysical studies of substitute 1,2-diarylethenes: twisted intramolecular charge transfer fluorescence in dimethoxycyano-substituted 1,2-diarylethene," Journal of the Chemical Society, Perkin Trans. vol. 2, pp. 395-401, 2001.

[36] R. K. Chaudhuri, K. F. Freed, S. Chattopadhyay, U. S. Mahapatra, “Theoretical Studies of the Ground and Excited State Structures of Stilbene," Journal of Physical Chemistry A, vol. 117, pp. 9424-9434, 2013. 
[37] W.-G. Han, T. Lovell, T. Liu, L. Noodleman, "Density Functional Studies of the Ground- and Excited-State Potential-Energy Curves of Stilbene cis - trans Isomerisation," Chemphyschem, vol. 3, pp. 167-178, 2002.

[38] R. Moreno-Fuquen, R. Dvries, J. Theodoro and J. Ellena, "4-\{2-[4-(Dimethylamino) phenyl] ethylidene \} benzonitrile," Acta Crystallographica Section E: Structure Reports Online, vol. 65, no. 6, pp. o1371-o1371, 2009.

[39] G. R. Pettit, B. E. Toki, D. L. Herald, M. R. Boyd, E. Hamel, R. K. Pettit and J. C. Chapuis, "Antineoplastic Agents. 410. Asymmetric Hydroxylation of trans-Combretastatin A-4 1," Journal of medicinal chemistry, vol. 42, no. 8, pp. 1459-1465, 1999.

[40] S. P. Kwasniewski, L. Claes, J.-P. François and M. S. Deleuze, "High level theoretical study of the structure and rotational barriers of trans-stilbene," The Journal of chemical physics, vol. 118, no. 17, pp. 7823-7836, 2003.

[41] L. Gutiérrey-Arzaluz, T. Rocha-Rinza, F. Cortés-Guzmán, "Stilbene photoisomerization driving force as revealed by the topology of the electron density and QTAIM properties," Computational and Theoretical Chemistry, vol. 1053, pp. 214-219, 2015.

[42] C. Jiang, R, Xie, F. Li, R. E. Allen, "Trans-to-cis isomerization of stilbene following an ultrafast laser pulse,” Chemical Physics Letters, vol. 474, pp. 263-267, 2009.

[43] R. Daum, T. Hansson, R. Nörenberg, D. Schwarzer and J. Schroeder, "Spectroscopy and dynamics of jet-cooled 4-dimethylamino-4'-cyanostilbene in the S 1 state," Chemical physics letters, vol. 246, no. 6, pp. 607-614, 1995.

[44] D. Jacquemin, V. Wathelet, E. A. Perpete and C. Adamo, "Extensive TD-DFT benchmark: singlet-excited states of organic molecules," Journal of Chemical Theory and Computation, vol. 5, no. 9, pp. 2420-2435, 2009.

[45] E. Lippert, „Spektroskopische Bestimmung des Dipolmomentes aromatischer Verbindungen im ersten angeregten Singulettzustand, “Zeitschrift f für Electrochemie, vol. 61, no. 957, pp. 962-975, 1957.

[46] N. Mataga, Y. Kaifu, M. Koizumi, "Solvent effects upon fluorescence spectra and the dipole moments of excited molecules," Bulletin of the Chemical Society of Japan, vol. 29, pp. 465-475, 1956. 
[47] G. M. Anstead, J.A.Katzenellenbogen, "Fluorescence properties of 2,3-diarylindenes," Journal of Physical Chemistry, vol. 92, pp. 6249-6258, 1988.

[48] R. C. Hilborn, 'Einstein coefficients, cross sections, f values, dipole moments, and all that,” American Journal of Physics, vol. 50, no. 11, pp. 982-994, 1982.

[49] D. H. Waldeck, "Photoisomerization dynamics of stilbenes," Chemical Reviews, vol. 91, no. 3, pp. 415-436, 1991.

[50] N. Holzmann, R. H. Bisby, A. W. Parker, L. Bernasconi, in preparation. 
Graphical abstract
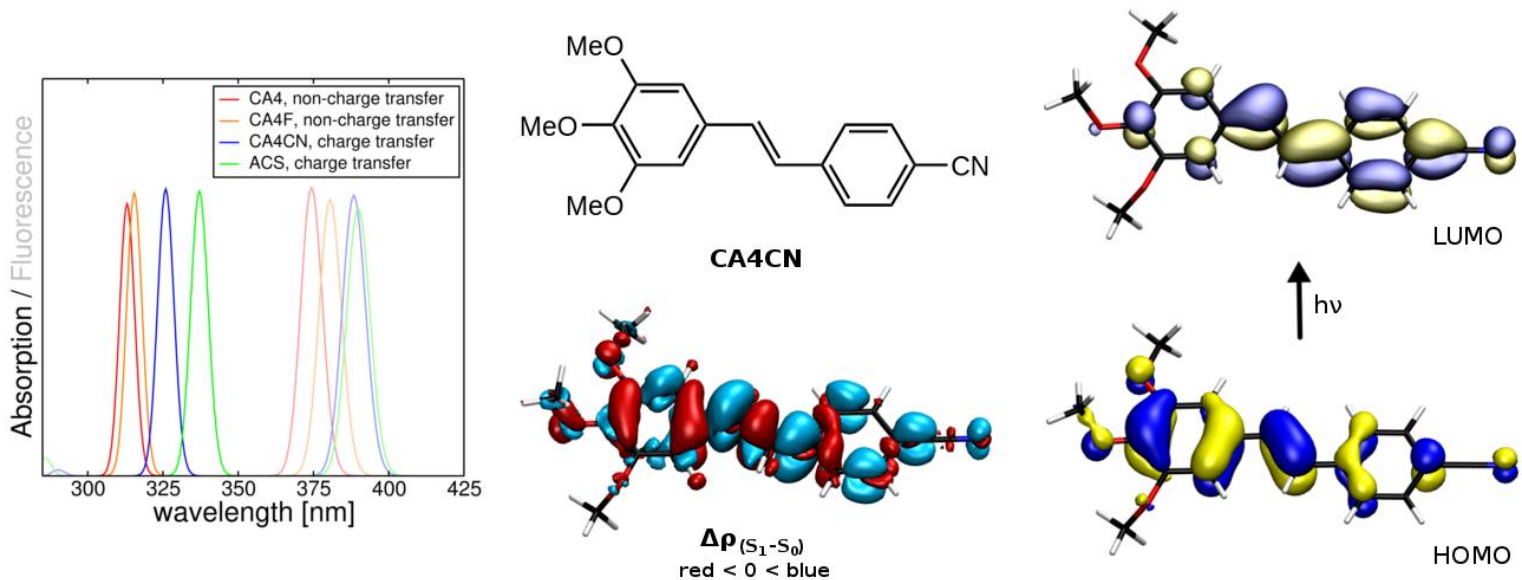


\section{Highlights}

- photoexcitation of non-toxic trans stilbene derivatives for application in local cancer therapy

- charge transfer character shifts multiphoton absorption wavelengths into tissue penetrating regions

- charge transfer effect pulls electron density towards vinyl bond increasing bond order in $\mathrm{S}_{1}$ state 